\title{
Optical and infrared
}

spectroelectrochemical studies of $\mathrm{CN}$ substituted bipyridyl complexes of

Ruthenium(II)

\section{Article}

Published Version

Creative Commons: Attribution-Noncommercial-No Derivative Works 4.0

Open Access

Taylor, J. O., Pizl, M., Kloz, M., Rebarz, M., McCuster, C. E., McCuster, J. K., Zalis, S., Hartl, F. and Vlcek, A. (2021) Optical and infrared spectroelectrochemical studies of CNsubstituted bipyridyl complexes of Ruthenium(II). Inorganic Chemistry, 60 (6). pp. 3514-3523. ISSN 0020-1669 doi: https://doi.org/10.1021/acs.inorgchem.0c03579 Available at https://centaur.reading.ac.uk/97651/

It is advisable to refer to the publisher's version if you intend to cite from the work. See Guidance on citing.

To link to this article DOI: http://dx.doi.org/10.1021/acs.inorgchem.0c03579

Publisher: American Chemical Society

All outputs in CentAUR are protected by Intellectual Property Rights law, including copyright law. Copyright and IPR is retained by the creators or other copyright holders. Terms and conditions for use of this material are defined in the End User Agreement. 


\section{www.reading.ac.uk/centaur}

\section{CentAUR}

Central Archive at the University of Reading

Reading's research outputs online 


\title{
Optical and Infrared Spectroelectrochemical Studies of CN- Substituted Bipyridyl Complexes of Ruthenium(II)
}

\author{
James O. Taylor, Martin Pižl, Miroslav Kloz, Mateusz Rebarz, Catherine E. McCusker, \\ James K. McCusker, Stanislav Zálišs, František Hartl,* and Antonín Vlček*
}

Cite This: Inorg. Chem. 2021, 60, 3514-3523

Read Online

\section{ACCESS 1}

Џ Metrics \& More

Article Recommendations

Supporting Information

ABSTRACT: Ruthenium(II) polypyridyl complexes $[\mathrm{Ru}(\mathrm{CN}$ Me-bpy $\left.)_{x}(\text { bpy })_{3-x}\right]^{2+}\left(\mathrm{CN}-\mathrm{Me}-\right.$ bpy $=4,4^{\prime}$-dicyano-5,5' -dimethyl$2,2^{\prime}$-bipyridine, bpy $=2,2^{\prime}$-bipyridine, and $x=1-3$, abbreviated as $1^{2+}, 2^{2+}$, and $\left.3^{2+}\right)$ undergo four $\left(1^{2+}\right)$ or five $\left(2^{2+}\right.$ and $\left.3^{2+}\right)$ successive one-electron reduction steps between -1.3 and $-2.75 \mathrm{~V}$ versus ferrocenium/ferrocene $\left(\mathrm{Fc}^{+} / \mathrm{Fc}\right)$ in tetrahydrofuran. The $\mathrm{CN}-\mathrm{Me}$-bpy ligands are reduced first, with successive one-electron reductions in $2^{2+}$ and $3^{2+}$ being separated by $150-210 \mathrm{mV}$; reduction of the unsubstituted bpy ligand in $\mathbf{1}^{2+}$ and $2^{2+}$ occurs only when all CN-Me-bpy ligands have been converted to their radical anions. Absorption spectra of the first three reduction

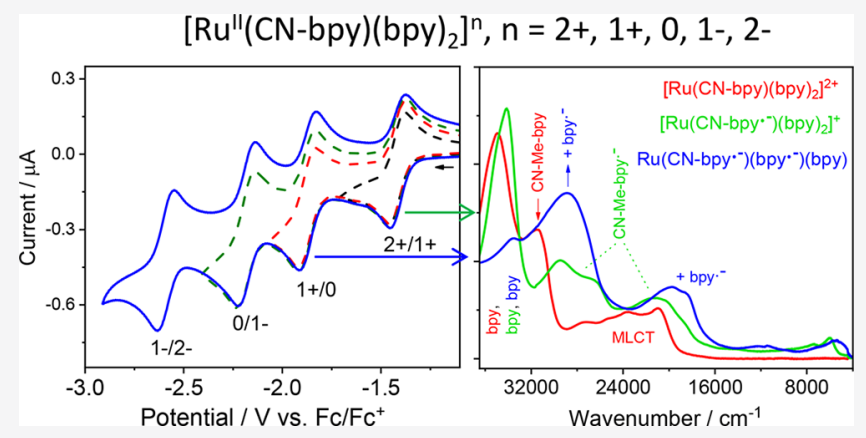
products of each complex were measured across the UV, visible, near-IR (NIR), and mid-IR regions and interpreted with the help of density functional theory calculations. Reduction of the CN-Mebpy ligand shifts the $\nu(\mathrm{C} \equiv \mathrm{N})$ IR band by ca. $-45 \mathrm{~cm}^{-1}$, enhances its intensity $\sim 35$ times, and splits the symmetrical and antisymmetrical modes. Semireduced complexes containing two and three $\mathrm{CN}$-derivatized ligands $\mathbf{2}^{+}, \mathbf{3}^{+}$, and $3^{0}$ show distinct $\nu(\mathrm{C} \equiv$ $\mathrm{N})$ features due to the presence of both $\mathrm{CN}-\mathrm{Me}-\mathrm{bpy}$ and $\mathrm{CN}-\mathrm{Me}-\mathrm{bpy}{ }^{\bullet-}$, confirming that each reduction is localized on a single ligand. NIR spectra of $\mathbf{1}^{\mathbf{0}}, \mathbf{1}^{-}$, and $\mathbf{2}^{-}$exhibit a prominent band attributable to the CN-Me-bpy ${ }^{\bullet-}$ moiety between 6000 and 7500 $\mathrm{cm}^{-1}$, whereas bpy ${ }^{--}$-based absorption occurs between 4500 and $6000 \mathrm{~cm}^{-1}$; complexes $2^{+}, 3^{+}$, and $3^{0}$ also exhibit a band at ca. 3300 $\mathrm{cm}^{-1}$ due to a CN-Me-bpy ${ }^{--} \rightarrow \mathrm{CN}-\mathrm{Me}$-bpy interligand charge-transfer transition. In the UV-vis region, the decrease of $\pi \rightarrow \pi^{*}$ intraligand bands of the neutral ligands and the emergence of the corresponding bands of the radical anions are most diagnostic. The first reduction product of $\mathbf{1}^{2+}$ is spectroscopically similar to the lowest triplet metal-to-ligand charge-transfer excited state, which shows pronounced NIR absorption, and its $\nu(\mathrm{C} \equiv \mathrm{N})$ IR band is shifted by $-38 \mathrm{~cm}^{-1}$ and 5-7-fold-enhanced relative to the ground state.

\section{INTRODUCTION}

Ruthenium(II) polypyridine complexes keep attracting attention for their rich photophysical, photochemical, and electrochemical properties that underlie their use as photoredox catalysts, solar-cell sensitizers, or electrochromic materials. Their photophysics and electrochemistry pose long-standing fundamental questions about localization of the excited electron or the electron added in a reduction process, interactions between polypyridyl ligands, intramolecular vibrational redistribution and vibrational relaxation following optical excitation, or an electron-storage capacity in the redox series. For many ruthenium(II) polypyridyl complexes, these features have been addressed by time-resolved absorption spectroscopy and spectroelectrochemistry in the UV-vis-near-IR (NIR) region, as well as by photoluminescence spectroscopy, which are traditional methods of choice. IR absorption has an additional advantage of structure sensitivity, but its applications to ruthenium(II) polypyridyl complexes ${ }^{1-3}$ have been rather rare because of the absence of suitable IR-active tags.
Excited-state time-resolved IR (TRIR) spectroscopy and IR spectroelectrochemistry are best applicable to molecules labeled with strong IR chromophores that exhibit intense absorption bands spectrally detached from the crowded mid-IR ("fingerprint") region. Metal carbonyl, amide, ester, azide, thiocyanide, or nitrile groups are typical IR tags used to investigate diverse processes ranging from enzyme dynamics and ultrafast relaxation to molecular structural changes upon electrochemical reduction or oxidation. ${ }^{4-11}$

Complexes $\left[\mathrm{Ru}(\mathrm{CN}-\mathrm{Me}-\mathrm{bpy})_{x}(\mathrm{bpy})_{3-x}\right]^{2+}(x=1-3$ for compounds $1^{2+}, 2^{2+}$, and $3^{2+}$, respectively, where CN-Me-bpy $=4,4^{\prime}$-dicyano-5, $5^{\prime}$-dimethyl-2,2'-bipyridine and bpy $=2,2^{\prime}$ -

Received: December 7, 2020

Published: March 1, 2021 
bipyridine; Chart 1) have been synthesized ${ }^{12}$ with the goal of developing a chromophore platform for probing vibrational

Chart 1. Schematic Molecular Structures of Complexes $1^{2+}$ $3^{2+}$

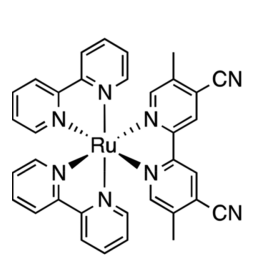

1

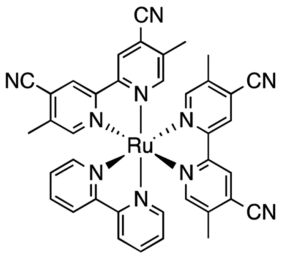

2

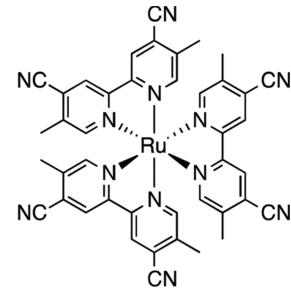

3 relaxation dynamics in metal-to-ligand charge-transfer (MLCT) excited states. The CN-Me-bpy ligand installs $-\mathrm{C} \equiv \mathrm{N}$ groups in the 4 and $4^{\prime}$ positions in order to couple them to the $\pi^{*}$ (bpy) lowest unoccupied molecular orbital (LUMO), thereby enabling them to act as reporters for dynamics within the MLCT excited-state manifold; $\mathrm{CH}_{3}$ groups in the 5 and $5^{\prime}$ positions serve to increase the basicity of the $\mathrm{N}$-donor atoms and improve the stability of the resulting metal complexes. Owing to its better $\pi$-accepting properties, the CN-Me-bpy ligand(s) in heteroleptic ruthenium(II) complexes $\mathbf{1}^{2+}$ and $2^{2+}$ is (are) reduced first, ca. $480 \mathrm{mV}$ more positively than bpy. ${ }^{12}$ The redox-potential splitting between the successive CN-Me-bpy reductions in $3^{2+}(180 \mathrm{mV}$ average $)$ is slightly smaller than that in $\left[\mathrm{Ru}(\mathrm{bpy})_{3}\right]^{2+}(220$ $\mathrm{mV}$ ), suggesting a slightly weaker ligand-ligand interaction. Interestingly, replacing bpy by $\mathrm{CN}-\mathrm{Me}$-bpy shifts the $\mathrm{Ru}^{\mathrm{III} / \mathrm{II}}$ potentials positively by about $130 \mathrm{mV}$ per ligand because of the weaker $\sigma$ donation and stronger $\pi$ back-bonding stabilizing occupied $\mathrm{Ru}^{\mathrm{II}} 4 \mathrm{~d}_{\pi}$ orbitals. ${ }^{12} \mathrm{Ru} \rightarrow$ CN-Me-bpy MLCT electronic transitions in heteroleptic complexes $\mathbf{1}^{2+}$ and $2^{2+}$ give rise to a distinct absorption feature at $\sim 480 \mathrm{~nm}$, but its red shift from the $\mathrm{Ru} \rightarrow$ bpy MLCT band $(\sim 420 \mathrm{~nm})$ is relatively small because the effect of the lower $\mathrm{CN}-\mathrm{Me}$-bpy $\pi^{*}$ energy is partially offset by a lower $\mathrm{Ru}^{\mathrm{II}} 4 \mathrm{~d}_{\pi}$ energy. ${ }^{12,13}$ The lowestenergy excited state in all three compounds (denoted as $* \mathbf{1}^{2+}$, $* 2^{2+}$, and $* 3^{2+}$ ) corresponds to a ${ }^{3}$ MLCT state associated with the more easily reduced $\mathrm{CN}-\mathrm{Me}-\mathrm{bpy}$ ligand, with photophysical properties that can be understood in terms of delocalization of the excited electron in a $\pi^{*}$ orbital that envelopes a single CN-Me-bpy ligand. ${ }^{12,13}$ Specifically, the more extended delocalization of the $\pi^{*}$ orbital of CN-Me-bpy due to conjugation with the $\mathrm{CN}$ groups increases the transition dipole moment and decreases the excited-state structural distortion relative to the ground state, resulting in a small increase of the radiative decay rate constant and a larger decrease of the nonradiative decay rate constant. Consequently, all three complexes are strongly luminescent with radiative quantum yields and excited-state lifetimes that systematically increase with increasing number of $\mathrm{CN}-\mathrm{Me}-$ bpy ligands in the coordination sphere. ${ }^{12}$ These excited-state properties, together with the $* 3^{2+} / 3^{+}$redox potential of ca. $+1.37 \mathrm{~V}$ versus normal hydrogen electrode, make $3^{2+}$ a strong photooxidant and a promising photocatalyst, although it has not been tested in this role yet.

TRIR spectroscopy was critical in confirming localization of the lowest-lying ${ }^{3} \mathrm{MLCT}$ to a CN-Me-bpy ligand. ${ }^{12,13}$ Namely, the IR absorption band due to the $\mathrm{C} \equiv \mathrm{N}$ stretching vibration,
$\nu(\mathrm{C} \equiv \mathrm{N})$, shifted upon excitation by $-38 \mathrm{~cm}^{-1} \cdot{ }^{12}$ Virtually identical IR responses to excitation were observed for all three complexes, regardless of the number of CN-Me-bpy ligands, establishing that the excited electron density in the lowest MLCT triplet state is indeed localized on a single CN-Me-bpy ligand; ultrafast TRIR spectroscopy has shown that this is the case from at least a few hundreds of femtoseconds after excitation. ${ }^{13}$ The common CN-Me-bpy localization of the excited and electrochemically added electron predicts similar spectroscopic responses to optical excitation and electrochemical reduction, despite different total numbers of electrons in the respective products.

In the present study, we explored the effects of excitation and electrochemical reduction on complexes $1^{2+}, 2^{2+}$, and $3^{2+}$, making use of the $\nu(\mathrm{C} \equiv \mathrm{N})$ IR absorption features, focusing not only on the spectral shifts but also their intensities and band shapes. Moreover, we have examined low-lying electronic transitions in the NIR region as a function of the electronic and redox states. While the analogy with the ${ }^{3} \mathrm{MLCT}$ excited state is rigorously valid only for the first reduction product, we have taken advantage of the rich electrochemistry associated with this series of compounds and characterized the second and third reduction products, acquiring information on electron localization and ligand-ligand interactions along the $[\mathrm{Ru}(\mathrm{CN}-$ Me-bpy $\left.)_{x}(\text { bpy })_{3-x}\right]^{n}$ redox series $(n=2+, 1+, 0$, and, in some cases, $1-)$.

\section{EXPERIMENTAL SECTION}

Materials. The samples were prepared and characterized as described previously. ${ }^{12}$ All electrochemical measurements were conducted under a strictly inert atmosphere of dry argon, using standard Schlenk techniques. The solvent, tetrahydrofuran (THF), was freshly distilled under a dinitrogen atmosphere from a mixture of sodium/benzophenone. The supporting electrolyte, tetrabutylammonium hexafluorophosphate (TBAH, Acros-Organics), was recrystallized twice from absolute ethanol and then dried for several hours under vacuum at ca. $100{ }^{\circ} \mathrm{C}$. Prior to use, the electrolyte was dried for a second time overnight (ca. $12 \mathrm{~h}$ ) at $120^{\circ} \mathrm{C}$.

Cyclic voltammograms (CVs) were recorded on a PGSTAT302N potentiostat (Metrohm Autolab) under an argon atmosphere, using an airtight three-electrode one-compartment cell. A Pt-disk microelectrode served as the working electrode, while coiled $\mathrm{Pt}$ and $\mathrm{Ag}$ wires, protected by glass mantles, served as counter and pseudoreference electrodes, respectively. Ferrocene $(\mathrm{Fc})$ was used as an internal standard, added at the end of each measurement. All reported potentials are referenced against the $\mathrm{Fc}^{+} / \mathrm{Fc}$ couple. The CV samples contained $0.1 \mathrm{M}$ TBAH as a supporting electrolyte and a 1 $\mathrm{mM}$ analyte.

UV-Vis-NIR-IR Spectroelectrochemistry. Spectroelectrochemical (SEC) measurements were conducted within an optically transparent thin-layer electrochemical (OTTLE) cell (Spectroelectrochemistry Reading). ${ }^{14}$ The OTTLE cell was equipped with a $\mathrm{Pt}$ minigrid working electrode, a $\mathrm{Pt}$ counter electrode, a $\mathrm{Ag}$ wire pseudoreference electrode, and $\mathrm{CaF}_{2}$ windows. SEC samples contained $3 \times 10^{-1} \mathrm{M} \mathrm{TBAH}$ as a supporting electrolyte and either $5 \mathrm{mM}$ (IR) or $1-2 \mathrm{mM}$ (UV-vis-NIR) analyte. IR SEC $(\tilde{\nu}<7500$ $\mathrm{cm}^{-1}$ ) was run on a Bruker Vertex 70v Fourier transform infrared spectrometer equipped with a DTLaGS detector. PerkinElmer Lamba 900 UV-vis-NIR double-beam and Scinco S-3100 diode-array spectrophotometers were used for UV-vis-NIR (40000-4450 $\mathrm{cm}^{-1}$ ) and UV-vis SEC experiments, respectively. The electrochemical response during the SEC experiments was recorded in the form of a thin-layer CV on an Emstat3 potentiostat (PalmSens) at a scan rate of $2 \mathrm{mV} \mathrm{s}^{-1}$.

Density Functional Theory (DFT) Calculations. All calculations were performed with Gaussian16, revision A03 (G16), ${ }^{15}$ together with the three-parameter Becke-Lee-Yang-Parr (B3LYP) 
functional. ${ }^{16,17}$ For the Ru atom, we used a quasi-relativistic effectivecore pseudopotential and a corresponding optimized basis set. ${ }^{18}$ For nonmetal atoms, we used the $6-311 \mathrm{G}(\mathrm{d})$ basis set. ${ }^{19}$ Solvent effects [THF and acetonitrile $(\mathrm{MeCN})]$ were described by the polarizable continuum model. ${ }^{20}$ Open-shell systems were calculated by the unrestricted Kohn-Sham (UKS) approach. Time-dependent DFT (TDDFT) was used to calculate electronic transitions and analyze them in terms of contributing one-electron excitations. ${ }^{21}$

\section{RESULTS AND DISCUSSION}

Cyclic Voltammetry. Values of the redox potentials of complexes $1^{2+}-3^{2+}$ measured in THF are similar to those reported previously ${ }^{12}$ in $\mathrm{MeCN}$ (Table 1). The following

Table 1. Electrochemical Reduction Potentials $\left(E_{1 / 2}, \mathrm{~V}\right.$, vs $\mathrm{Fc}^{+} / \mathrm{Fc}$ ) of Complexes $1-3$ in THF/TBAH at $298 \mathrm{~K}$ and the Values Reported ${ }^{12}$ in $\mathrm{MeCN}$

$\begin{array}{lllll}\text { complex } & 2+/ 1+ & 1+/ 0 & 0 / 1- & 1-/ 2- \\ \mathbf{1}(\mathrm{THF}) & -1.42 & -1.88 & -2.18 & -2.59 \\ \mathbf{1}(\mathrm{MeCN}) & -1.38 & -1.86 & -2.06 & \\ \mathbf{2}(\mathrm{THF}) & -1.34 & -1.46 & -2.02 & -2.39^{a} \\ \mathbf{2}(\mathrm{MeCN}) & -1.33 & -1.52 & -1.99 & \\ \mathbf{3}(\mathrm{THF}) & -1.31 & -1.40 & -1.60 & -2.27^{b} \\ \mathbf{3}(\mathrm{MeCN}) & -1.25 & -1.40 & -1.61 & \end{array}$

${ }^{a}$ Additional fifth reduction indicated at ca. $-2.75 \mathrm{~V} .{ }^{b}$ Additional fifth reduction indicated at ca. $-2.5 \mathrm{~V}$.

discussion will use values obtained in $\mathrm{MeCN}$, noting that the THF data lead to the same conclusions. The CV of $\mathbf{1}^{2+}$ in THF showed four reduction steps that are both chemically and electrochemically reversible at a $100 \mathrm{mV} \mathrm{s}^{-1}$ scan rate (Figure $1)$. Complexes $2^{2+}$ and $3^{2+}$ also exhibited four reversible or quasireversible reduction peaks, the first three of which were more closely spaced and, hence, less well resolved than that for $\mathbf{1}^{\mathbf{2 +}}$ (Figures S1 and S2). A fifth reduction was indicated for $\mathbf{2}^{\mathbf{2 +}}$ and $3^{2+}$ at most negative potentials.

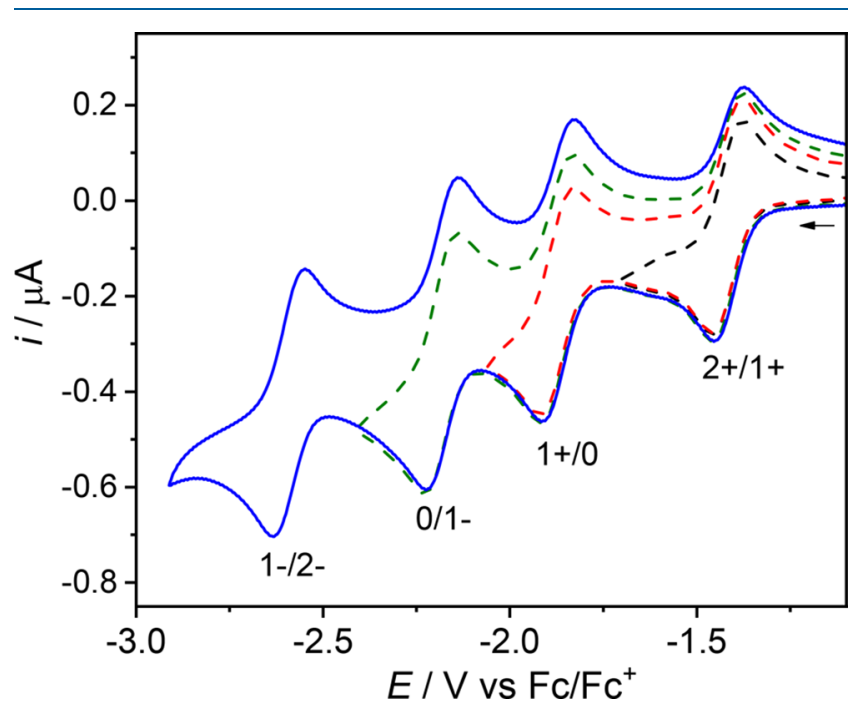

Figure 1. CVs of $\mathbf{1}^{2+}$ in THF/TBAH at room temperature. $\mathrm{Pt}$ microdisk electrode. Scan rate: $100 \mathrm{mV} \mathrm{s}^{-1}$. The arrow indicates the initial scan direction. Black, red, green, and blue curves: potential scan reversed after the first, second, third, and fourth reduction waves, respectively. Cathodic and anodic peaks are separated by $80-90 \mathrm{mV}$, which is comparable with the $\mathrm{Fc}^{+} / \mathrm{Fc}$ couple measured at identical conditions.
Spacing between successive reduction potentials and their values provide initial information on the localization of individual redox steps. ${ }^{2-27}$ The first reduction of $1^{2+}-3^{2+}$ occurs $320-420 \mathrm{mV}$ more positively than that of $\left[\mathrm{Ru}(\mathrm{bpy})_{3}\right]^{2+}$ $(-1.70 \mathrm{~V}$ in $\mathrm{MeCN})$, suggesting its localization on the $\mathrm{CN}$ Me-bpy ligand. Hence, the one-electron-reduced complexes of all three members of the series can be formulated as $[\mathrm{Ru}(\mathrm{CN}$ Me-bpy $\left.\left.{ }^{\bullet-}\right)(\mathrm{CN}-\mathrm{Me}-\mathrm{bpy})_{y}(\mathrm{bpy})_{2-y}\right]^{+}(y=0-2) ;^{12}$ this is supported by a DFT calculation of the spin density in $\mathbf{1}^{+}$, which reveals localization of the unpaired electron on the $\mathrm{CN}$ Me-bpy ligand (Figure S3, left). The large gap between the first and second reduction potentials of $\mathbf{1}^{2+}(-480 \mathrm{mV})$ and the similarity of the second $\mathbf{1}^{2+}$ reduction potential $(-1.86 \mathrm{~V}$ in $\mathrm{MeCN})$ with the first and second $\left[\mathrm{Ru}(\mathrm{bpy})_{3}\right]^{2+}$ potentials $(-1.70$ and $-1.89 \mathrm{~V})$ strongly suggest that the $\mathbf{1}^{+} \rightarrow \mathbf{1}^{0}$ step is localized at bpy, producing $\left[\mathrm{Ru}^{\mathrm{II}}\left(\mathrm{CN}-\mathrm{Me}-\mathrm{bpy}^{\bullet-}\right)\left(\mathrm{bpy}^{\bullet-}\right)\right.$ (bpy)] $\left(\mathbf{1}^{0}\right)$. Much smaller gaps between the first and second reduction potentials were observed for $2^{2+}(190 \mathrm{mV})$ and $3^{2+}$ $(150 \mathrm{mV})$. Potential gaps of this magnitude in ruthenium(II) polypyridyl complexes typically originate from ligand-ligand interactions ${ }^{22-27}$ and are consistent with the second reduction process being associated with the second $\mathrm{CN}-\mathrm{Me}-\mathrm{bpy}$ ligand in the coordination sphere, producing $\left[\mathrm{Ru}^{\mathrm{II}}(\mathrm{CN}-\mathrm{Me}-\right.$ $\left.\left.\mathrm{bpy}^{\bullet-}\right)_{2}(\mathrm{bpy})\right]\left(\mathbf{2}^{\mathbf{0}}\right)$ and $\left[\mathrm{Ru}^{\mathrm{II}}\left(\mathrm{CN}-\mathrm{Me}-\mathrm{bpy}{ }^{\bullet-}\right)_{2}(\mathrm{CN}-\mathrm{Me}-\mathrm{bpy})\right]$ $\left(3^{0}\right)$. The small gap between the second and third reduction potentials of $\mathbf{1}^{2+}$ and $3^{2+}$ suggests that the third reduction is localized at the remaining unreduced ligand of the same kind as that involved in the preceding step, i.e., bpy and CN-Mebpy, respectively. This is corroborated by the $1^{0} / 1^{-}$potential $(-2.06 \mathrm{~V})$ being close to the third reduction potential of $\left[\mathrm{Ru}(\mathrm{bpy})_{3}\right]^{2+}(-2.14 \mathrm{~V})$, whereas the $3^{0} / 3^{-}$potential is significantly less negative $(-1.61 \mathrm{~V})$. On the other hand, the third reduction of $2^{2+}$ occurs $470 \mathrm{mV}$ more negatively than the second one: the observed potential of $-1.99 \mathrm{~V}$ (in $\mathrm{MeCN}$ ) is comparable with the third reduction of $\left[\mathrm{Ru}(\mathrm{bpy})_{3}\right]^{2+}$, suggesting bpy localization. It follows that the third reduction always concerns the last remaining unreduced ligand, producing $\left[\mathrm{Ru}^{\mathrm{II}}\left(\mathrm{CN}-\mathrm{Me}-\mathrm{bpy}^{\bullet-}\right)\left(\mathrm{bpy}^{\bullet-}\right)_{2}\right] \quad\left(\mathbf{1}^{-}\right), \quad\left[\mathrm{Ru}^{\mathrm{II}}(\mathrm{CN}-\right.$ Me-bpy $\left.^{\bullet-}\right)_{2}\left(\right.$ bpy $\left.\left.^{\bullet-}\right)\right]\left(2^{-}\right)$, and $\left[\mathrm{Ru}^{\mathrm{II}}\left(\mathrm{CN}-\mathrm{Me}-\mathrm{bpy}{ }^{\bullet-}\right)_{3}\right]\left(3^{-}\right)$. Localizations of the first three reduction steps were confirmed by spectroelectrochemistry in the IR as well as UV-vis and NIR spectral regions (vide infra).

The fourth (and for $2^{2+}$ and $3^{2+}$ also the fifth) reduction steps are presumably localized at $\mathrm{CN}-\mathrm{Me}-\mathrm{bpy}^{\bullet-}$, producing complexes of a doubly reduced $\mathrm{CN}-\mathrm{Me}-\mathrm{bpy}^{2-}$. Although these reductions are indicated in the cyclic voltammograms, the low stability of their products precluded any detailed SEC characterization.

IR Spectroelectrochemistry in the $\nu(\mathrm{C} \equiv \mathrm{N})$ Region. IR spectral changes in the course of successive electrochemical reductions are displayed in Figure 2, and the $\nu(\mathrm{C} \equiv \mathrm{N})$ wavenumbers of individual redox products are summarized in Table 2. Parent complexes $\mathbf{1}^{\mathbf{2 +}}-\mathbf{3}^{2+}$ showed a single weak Lorentzian band at $2236 \mathrm{~cm}^{-1}$ attributable to quasidegenerate antisymmetric $\left(B_{1}\right)$ and symmetric $\left(A_{1}\right)$ stretching vibrations of the two $\mathrm{C} \equiv \mathrm{N}$ groups. (The symmetry labels refer to the $C_{2 v}$ local point group of the CN-Me-bpy ligand.) The DFTcalculated $A_{1}$ IR intensity in $\mathbf{1}^{2+}$ was 1.8 times larger than the $\mathrm{B}_{1}$ intensity (Table 3 ), contrary to a qualitative expectation that the local dipole-moment change will be smaller for a totally symmetric vibration. A CN-Me-bpy-localized reduction shifted the $\nu(\mathrm{C} \equiv \mathrm{N})$ feature to lower wavenumbers, removed the degeneracy of $B_{1}$ and $A_{1}$ vibrations, and increased the total 

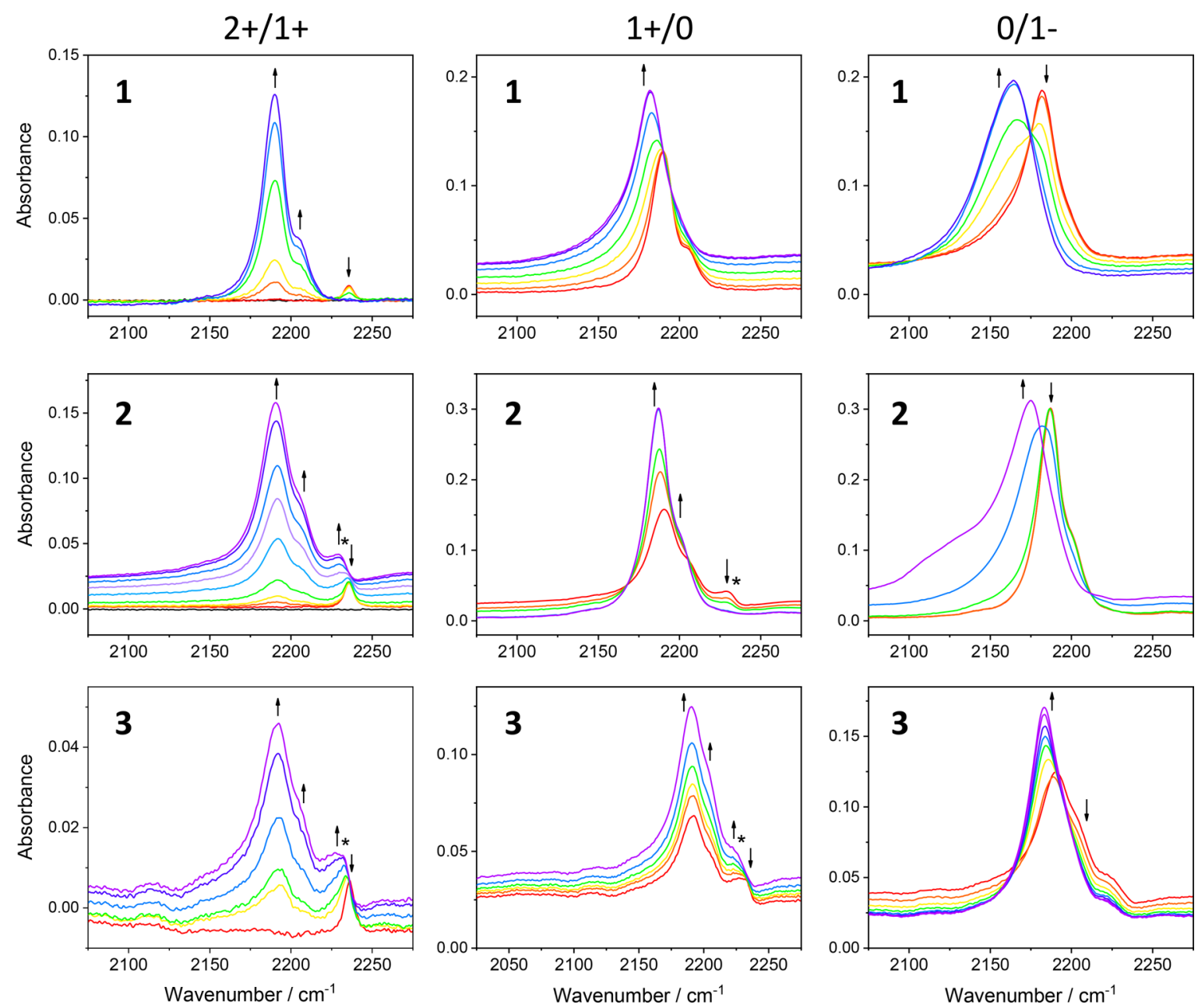

Figure 2. IR SEC monitoring of the $\nu(\mathrm{C} \equiv \mathrm{N}$ ) band in complexes 1 (top), 2 (middle), and 3 (bottom) during successive reductions $2+\rightarrow 1+$ (left), $1+\rightarrow 0$ (center), and $0 \rightarrow 1-$ (right). Measured in THF/TBAH at $298 \mathrm{~K}$ in an OTTLE cell. Asterisks denote the bands due to the unreduced CN-Me-bpy ligand in semireduced 2 and 3. ( $1^{-}$decomposed in the SEC cell in a few minutes, producing an unidentified species whose IR spectrum is shown in Figure S4. The broad shoulder around $2125 \mathrm{~cm}^{-1}$ in the $\mathbf{2}^{-}$spectrum belongs to a decomposition product. $3^{-}$was stable on the SEC time scale.) The apparent baseline drift was caused by the underlying electronic absorption in the NIR-IR region.

Table 2. IR Spectroscopic Data for 1-3 and Their Reduction Products in $\mathrm{THF}^{a}$

\begin{tabular}{|c|c|c|c|c|c|c|c|c|c|c|}
\hline \multirow[b]{3}{*}{ charge } & \multirow[b]{3}{*}{ assignment } & \multicolumn{9}{|c|}{$\nu(\mathrm{C} \equiv \mathrm{N}) / \mathrm{cm}^{-1}$} \\
\hline & & \multicolumn{3}{|c|}{1} & \multicolumn{3}{|c|}{2} & \multicolumn{3}{|c|}{3} \\
\hline & & & shift & $\operatorname{area}^{b}$ & & shift & $\operatorname{area}^{b}$ & & shift & $\operatorname{area}^{b}$ \\
\hline $2+$ & $A_{1}+B_{1}$ & 2236 & & 1 & 2236 & & 1 & 2236 & & 1 \\
\hline \multirow[t]{3}{*}{$1+$} & CN-Me-bpy & & & & 2229 & -7 & & 2227 & -9 & \\
\hline & $\mathrm{A}_{1}\left(\mathrm{CN}-\mathrm{Me}-\mathrm{bpy}^{\bullet-}\right)$ & 2207 & -29 & & 2207 & -29 & & 2207 & -29 & \\
\hline & $\mathrm{B}_{1}\left(\mathrm{CN}-\mathrm{Me}-\mathrm{bpy}^{\bullet-}\right)$ & 2190 & -46 & $33.5^{c}$ & 2191 & -45 & $15.4^{d}$ & 2192 & -44 & $\sim 12^{f}$ \\
\hline \multirow[t]{3}{*}{0} & CN-Me-bpy & & & & & & & 2222 & -14 & \\
\hline & $\mathrm{A}_{1}\left(\mathrm{CN}-\mathrm{Me}-\mathrm{bpy}^{\bullet-}\right)$ & $\sim 2190$ & -46 & & 2202 & -34 & & 2207 & -29 & \\
\hline & $\mathrm{B}_{1}\left(\mathrm{CN}-\mathrm{Me}-\mathrm{bpy}^{\bullet-}\right)$ & 2181 & -55 & & 2187 & -49 & $43.5^{e}$ & 2190 & -46 & \\
\hline \multirow[t]{2}{*}{$1-$} & CN-Me-bpy ${ }^{\bullet-}$ & 2164 & -72 & & 2175 & -61 & & 2196 & -40 & \\
\hline & & & & & & & & 2183 & -53 & $38^{g}$ \\
\hline
\end{tabular}

${ }^{a}$ The $\mathrm{A}_{1}$ and $\mathrm{B}_{1}$ wavenumbers and areas were obtained by Lorentzian fitting of the IR bands. ${ }^{b}$ Total band area relative to the parent. ${ }^{c} \mathrm{~B}_{1} / \mathrm{A}_{1}$ area ratio $=19 .{ }^{d}$ Area enhancement per $\mathrm{CN}-\mathrm{Me}$-bpy ligand $=30.8 ; \mathrm{B}_{1} / \mathrm{A}_{1}$ area ratio $=23 .{ }^{e} \mathrm{~B}_{1} / \mathrm{A}_{1}$ area ratio $=11.5 .{ }^{f}$ Area enhancement per $\mathrm{CN}-\mathrm{Me}-\mathrm{bpy}$ ligand $\cong 36 .{ }^{g} \mathrm{~B}_{1} / \mathrm{A}_{1}$ area ratio $=7.5$.

integrated band area approximately 35 times per reduced $\mathrm{CN}$ Me-bpy ligand, owing mostly to intensification of the antisymmetric $B_{1}$ mode (Tables 2 and 3 ). For example, the first reduction of $\mathbf{1}^{2+}$ to $\mathbf{1}^{+}$produced two overlapping Lorentzian bands downshifted by -29 and $-46 \mathrm{~cm}^{-1}$ in an integrated-intensity ratio of about 1:20 that are attributable to $\mathrm{A}_{1}$ and $\mathrm{B}_{1} \nu(\mathrm{C} \equiv \mathrm{N})$ vibrations, respectively. The total integrated $\nu(\mathrm{C} \equiv \mathrm{N})$ intensity increased upon reduction 34 times. This assignment was supported by DFT vibrational analysis, which produced downshifts of $-35 \mathrm{~cm}^{-1}\left(\mathrm{~A}_{1}\right)$ and 
Table 3. Calculated and Experimental $\nu(\mathrm{C} \equiv \mathrm{N})$ IR Spectroscopic Data for $1^{2+}$ in THF, Its Lowest Triplet Excited State $* 1^{2+}$ in $\mathrm{CH}_{3} \mathrm{NO}_{2}$, and Singly $\left(1^{+}\right)$and Doubly $\left(1^{0}\right)$ Reduced Forms in THF (Wavenumbers $(\tilde{\nu})$ in $\mathrm{cm}^{-1}$ and Calculated Intensities in $\mathrm{km} \mathrm{mol}^{-1}$ )

\begin{tabular}{|c|c|c|c|c|c|c|c|}
\hline species & $\nu(\mathrm{C} \equiv \mathrm{N})$ & $\exp \tilde{\nu}$ & calc (int.) & $\exp \tilde{\nu}$ shift & calc $\tilde{\nu}$ shift & exp enhanc & calc enhanc \\
\hline \multirow[t]{2}{*}{$1^{2+}$} & $A_{1}$ & 2236 & $2236(62)$ & & & 1 & 1 \\
\hline & $\mathrm{B}_{1}$ & 2236 & $2236(34)$ & & & & \\
\hline \multirow[t]{2}{*}{$* 1^{2+}$} & $A_{1}$ & 2214 & $2207(210)$ & -24 & -31 & $5-7^{a}$ & $10.4-14.7^{b}$ \\
\hline & $\mathrm{B}_{1}$ & 2200 & $2192(2237)$ & -38 & -46 & & \\
\hline \multirow[t]{2}{*}{$1^{+}$} & $A_{1}$ & 2207 & $2201(420)$ & -29 & -35 & 33.5 & 32 \\
\hline & $\mathrm{B}_{1}$ & 2190 & $2185(2636)$ & -46 & -51 & & \\
\hline \multirow[t]{2}{*}{$1^{0}$} & $A_{1}$ & $\sim 2189$ & $2194(502)$ & -47 & -42 & & \\
\hline & $\mathrm{B}_{1}$ & 2181 & $2172(3367)$ & -55 & -64 & & \\
\hline
\end{tabular}

${ }^{a}$ Depending on background subtraction. ${ }^{b}$ Values of 10.4 and 14.7 were obtained by TDDFT and UKS optimization of the lowest triplet state, respectively.
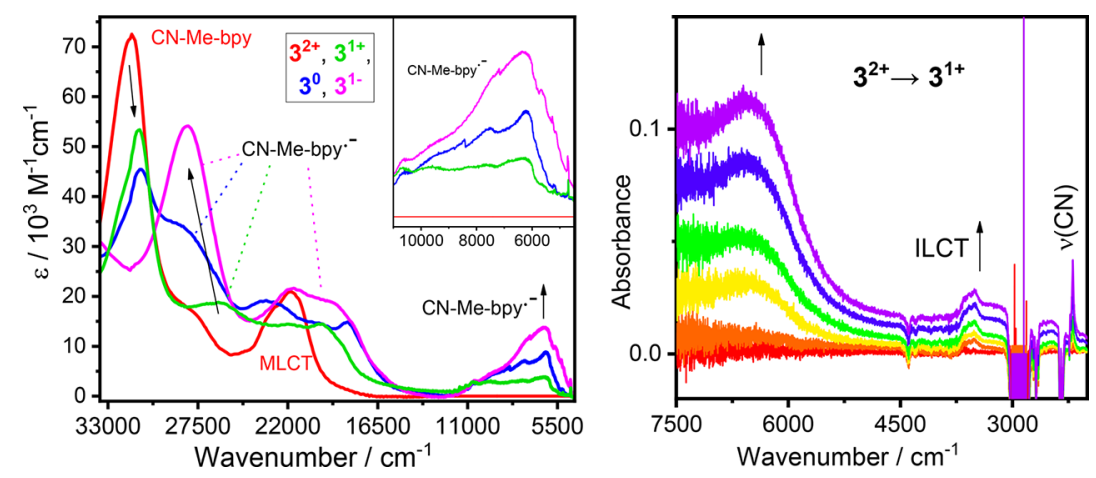

Figure 3. Left: UV-vis-NIR spectra of $3^{2+}$ and its reduction products in THF. Right: NIR-IR spectra monitored in the course of the first reduction of $3^{2+}$ in THF. For the second and third reduction steps, see Figure S5.

Table 4. UV-Vis-NIR Absorption Data for Complexes $1^{2+}-3^{2+}$ and Their Reduction Products in THF

\begin{tabular}{|c|c|c|c|}
\hline \multirow[b]{2}{*}{ charge } & \multicolumn{3}{|c|}{ UV-vis-NIR $\tilde{\nu} / \mathrm{cm}^{-1}$} \\
\hline & 1 & 2 & 3 \\
\hline $2+$ & $34950,31500,27200,25100(\mathrm{sh}), 23600,21000$ & $\begin{array}{l}36000,35000,31540,27350,25300(\mathrm{sh}), 22700(\mathrm{sh}), \\
\quad 21050\end{array}$ & $31560,28200(\mathrm{sh}), 22750(\mathrm{sh}), 21850$ \\
\hline $1+$ & $\begin{array}{l}34150,29500,27100(\mathrm{sh}), 21200,18900(\mathrm{sh}) \\
\quad 14500(\mathrm{sh}), 9400(\mathrm{sh}), 7400,6040\end{array}$ & $\begin{array}{l}34250,31050,26200,23800,19900,18800(\mathrm{sh}) \\
14500(\mathrm{sh}), 9200(\mathrm{sh}), 7600,6300\end{array}$ & $\begin{array}{l}31120,26300,21900,19980,18700(\mathrm{sh}) \\
\quad 9600,7600,6340\end{array}$ \\
\hline 0 & $\begin{array}{l}33560,28900,19760,18700(\mathrm{sh}), 12200,11450 \\
\quad 7000(\mathrm{sh}), 5840,4400(\mathrm{sh})\end{array}$ & $\begin{array}{l}33950,28460,23500,20200,18800(\mathrm{sh}), 14500(\mathrm{sh}) \\
\quad 9200(\mathrm{sh}), 7200,6000\end{array}$ & $\begin{array}{l}31030,28900(\mathrm{sh}), 23350,20100(\mathrm{sh}) \\
18350,9200(\mathrm{sh}), 7520,6200\end{array}$ \\
\hline $1-$ & $a$ & $a$ & $\begin{array}{l}28150,21700,19400,18100(\mathrm{sh}), 9200(\mathrm{sh}), \\
\quad 7400,6330\end{array}$ \\
\hline
\end{tabular}

${ }^{a}$ Not measured.

$-52 \mathrm{~cm}^{-1}\left(B_{1}\right)$ and a 32 -fold intensity enhancement. The IRband strengthening is indeed a remarkable effect that originates from electron-density redistribution upon reduction rather than changes in the molecular structure (vide infra). Virtually identical splittings, downshifts, intensity increases, and Lorentzian band shapes of the $\nu(\mathrm{C} \equiv \mathrm{N})$ band were observed for $\mathrm{2}^{+}$and $3^{+}$, confirming that the first reduction is in all cases localized at a single CN-Me-bpy ligand. Their total $\nu(\mathrm{C} \equiv \mathrm{N})$ band intensities are about 15.4 and 12 times higher compared to that of the parent, which corresponds to ca. 31- and 36-fold enhancement per CN-Me-bpy ligand reduced, respectively. In addition, the IR spectra of $2^{+}$and $3^{+}$displayed a very weak feature due to the remaining neutral $\mathrm{CN}$-Me-bpy (marked as asterisks in Figure 2) that was downshifted by $7(9) \mathrm{cm}^{-1}$ for $2^{+}\left(3^{+}\right)$and disappeared (diminished) in the course of the second reduction. For $3^{2+}$, it vanished after the third reduction to $3^{-}$because all three $\mathrm{CN}-\mathrm{Me}-\mathrm{b} p y$ ligands are singly reduced in this state.
Reduction of the second CN-Me-bpy ligand in the $2^{+} \rightarrow 2^{0}$ and $3^{+} \rightarrow 3^{0}$ steps approximately doubled the intensity of the $\mathrm{CN}-\mathrm{Me}-\mathrm{bpy}^{\bullet-} \nu(\mathrm{C} \equiv \mathrm{N})$ band. Both of its $\mathrm{B}_{1}$ and $\mathrm{A}_{1}$ components shifted downward by a few wavenumbers (Table 2). Similar spectral changes accompanied reduction of the last CN-Me-bpy ligand in $3^{0} \rightarrow 3^{-}$, whereby the $A_{1}$ and $B_{1}$ bands shifted by -11 and $-7 \mathrm{~cm}^{-1}$, respectively. The band area increased ca. 38 times upon 3 -fold $3^{2+}$ reduction. The bpylocalized reduction steps $\mathbf{1}^{+} \rightarrow \mathbf{1}^{0}, \mathbf{1}^{\mathbf{0}} \rightarrow \mathbf{1}^{-}$, and $\mathbf{2}^{\mathbf{0}} \rightarrow \mathbf{2}^{-}$ shifted the CN-Me-bpy ${ }^{\bullet-} \nu(\mathrm{C} \equiv \mathrm{N})$ feature by ca. $-17 \mathrm{~cm}^{-1}$ and diminished the $B_{1}-A_{1}$ splitting. For example, $B_{1}$ and $A_{1}$ bands underwent -9 and $-18 \mathrm{~cm}^{-1}$ shifts upon $\mathbf{1}^{+} \rightarrow \mathbf{1}^{\mathbf{0}}$ reduction, decreasing the $B_{1}-A_{1}$ splitting from 17 to $9 \mathrm{~cm}^{-1}$ and making the $A_{1}$ feature barely recognizable in Lorentzian or Voigt fits in the $\mathbf{1}^{\mathbf{0}}$ spectrum. This sensitivity of the $\nu(\mathrm{C} \equiv \mathrm{N})$ frequencies to the redox state of other ligands in the coordination sphere is probably caused by a ligand-ligand communication through the $\mathrm{Ru}^{\mathrm{II}}$ central atom: the reduction 

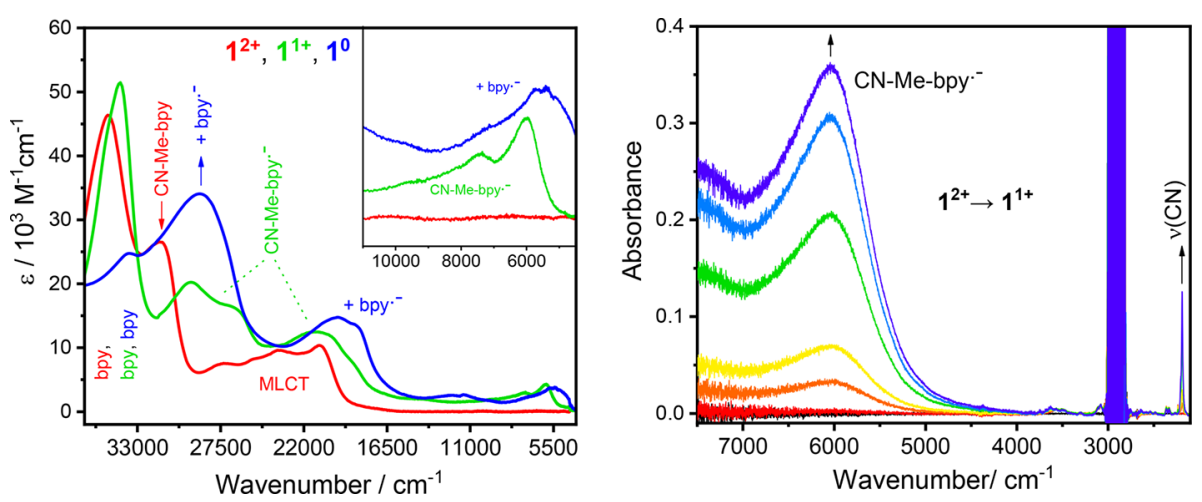

Figure 4. Left: UV-vis-NIR spectra of $\mathbf{1}^{2+}$ and its reduction products in THF. Right: NIR-IR spectra monitored in the course of the first reduction of $\mathbf{1}^{2+}$ in THF. For the second and third reduction steps, see Figure S6.

of $\mathrm{CN}-\mathrm{Me}$-bpy or bpy increases the electron density at $\mathrm{Ru}^{\mathrm{II}}$ by increased donation and/or decreased $\pi$ back-bonding, which affects other $\mathrm{CN}-\mathrm{Me}-\mathrm{bpy}$ or $\mathrm{CN}-\mathrm{Me}-\mathrm{bpy}^{\bullet-}$ ligands already present in the coordination sphere.

UV-Vis-NIR Spectroelectrochemistry. Changes in the electronic transitions accompanying successive reductions of the CN-Me-bpy ligands were evident from absorption spectra measured across the redox series for the homoleptic complex $3^{n}(n=2+, 1+, 0,1-$; Figure 3 and Table 4$)$. The $3^{2+}$ parent exhibited a typical spectrum of a ruthenium(II) tris(polypyridyl) complex consisting of a $\pi \rightarrow \pi^{*}(\mathrm{CN}-\mathrm{Me}-\mathrm{bpy})$ intraligand band at $31560 \mathrm{~cm}^{-1}(317 \mathrm{~nm})$ and an MLCT feature at $22800-21900 \mathrm{~cm}^{-1}(440-460 \mathrm{~nm})$. Successive reductions $3^{2+} \rightarrow 3^{+} \rightarrow 3^{0} \rightarrow 3^{-}$gradually diminished the intensity of the $\pi \rightarrow \pi^{*}(\mathrm{CN}-\mathrm{Me}-\mathrm{bpy})$ band until it ultimately vanished in $3^{-}$, i.e., once all three $\mathrm{CN}-\mathrm{Me}$-bpy ligands were reduced. The visible absorption feature around $450 \mathrm{~nm}$ broadened and red-shifted because $\mathrm{Ru}^{\mathrm{II}} \rightarrow \mathrm{CN}-\mathrm{Me}-\mathrm{bpy}$ MLCT transitions were gradually replaced by $\pi \rightarrow \pi^{*}(\mathrm{CN}$ $\mathrm{Me}^{-b p y^{-}}{ }^{-}$) transitions (assigned by analogy with reduced bpy $^{\bullet-}$ complexes $\left.^{28,29}\right)$. In the spectra of $3^{+}, 3^{\mathbf{0}}$, and $\mathbf{2}^{+}$, the shape and position of the $\sim 450 \mathrm{~nm}$ feature were also modified by $\mathrm{Ru}^{\mathrm{II}} \rightarrow \mathrm{CN}-\mathrm{Me}-$ bpy MLCT transitions shifting slightly to lower energies relative to the $3^{2+}$ or $2^{2+}$ parents because of the increasing electron density at $\mathrm{Ru}^{\mathrm{II}}$ and the concomitant destabilization of its $4 \mathrm{~d}_{\pi}$ orbitals. Reduced polypyridine complexes are typically characterized by a strong near-UV absorption band, found at $29200 \mathrm{~cm}^{-1}(342 \mathrm{~nm})^{29}$ for $\left[\mathrm{Ru}(\mathrm{bpy})_{3}\right]^{+}$or at $27700 \mathrm{~cm}^{-1}(361 \mathrm{~nm})$ for $\mathrm{ReCl}-$ $(\mathrm{CO})_{3}\left(\right.$ bpy $\left.^{\circ-}\right)$, where it was identified ${ }^{28}$ by TDDFT as a mixed $\pi \rightarrow \pi^{*}\left(\right.$ bpy $\left.^{\bullet-}\right) / \mathrm{Re}^{\mathrm{I}} \rightarrow$ bpy $^{\bullet-}$ intraligand/MLCT transition. In the $3^{n+}$ redox series, the corresponding feature emerged in $3^{+}$as a weak feature at $\sim 26300 \mathrm{~cm}^{-1}(380 \mathrm{~nm})$, and then blue-shifted and gained intensity upon the second and, especially, the third reduction, becoming a prominent band at $28150 \mathrm{~cm}^{-1}(355 \mathrm{~nm})$ in $3^{-}$. In the NIR region, a broad absorption band attributable to $\pi \rightarrow \pi^{*}\left(\mathrm{CN}-\mathrm{Me}-\mathrm{bpy}{ }^{\circ-}\right)$ transitions between 5000 and $10000 \mathrm{~cm}^{-1}$ appeared upon the first reduction and increased in intensity with each successive reduction step. Interestingly, NIR-IR spectra of $3^{+}$and $3^{0}$ showed an additional weak feature at about $3300 \mathrm{~cm}^{-1}$ (Figures 3, right, and S5). This feature was absent in the spectrum of the parent complex, $3^{2+}$, emerged upon the first reduction $\left(3^{2+} \rightarrow 3^{+}\right)$, increased in intensity upon the second reduction $\left(3^{+} \rightarrow 3^{0}\right)$, and vanished after the third one upon formation of $3^{-}$, whereas the CN-Me-bpy ${ }^{\bullet-}$-related NIR band around $6000 \mathrm{~cm}^{-1}$ continually increased across this sequence of reductions. This pattern suggests an electronic as opposed to a vibrational origin of the $\sim 3300 \mathrm{~cm}^{-1}$ transition. Because it was found only in complexes that simultaneously contain in their coordination spheres CN-Me-bpy and CN-Me-bpy ${ }^{\bullet-}$ ligands [the same absorption feature was observed in the spectrum of $2^{+}$(Figures 4 and S7)], we assign the $\sim 3300 \mathrm{~cm}^{-1}$ band to a CN-Me-bpy ${ }^{\bullet-} \rightarrow$ CN-Me-bpy interligand charge transfer (ILCT) transition.

UV-vis-NIR spectra of $1^{2+}, 2^{2+}$, and their first reduction products combine features due to $\mathrm{CN}-\mathrm{Me}$-bpy and bpy ligands and their reduced forms. This was manifested in the spectra of $\mathbf{1}^{n+}$ (Figures 4 and S6), where the $\pi \rightarrow \pi^{*}$ (bpy) band in the UV region retained its intensity and slightly red-shifted upon the first $\mathrm{CN}-\mathrm{Me}$-bpy-localized reduction and then strongly decreased in intensity upon the bpy-localized second step. $\mathrm{CN}$ Me-bpy ${ }^{\bullet-}$-associated transitions (Table S1) emerged after the first reduction $\left(1^{+}\right)$at $29500 \mathrm{~cm}^{-1}(339 \mathrm{~nm})$ and between 6000 and $8000 \mathrm{~cm}^{-1}$ in the NIR region, getting encompassed by overlapping stronger red-shifted bpy ${ }^{\circ-}$ absorption in $\mathbf{1}^{\mathbf{0}}$. Absorptions associated with the bpy ${ }^{\circ-}$ chromophore in the NIR continued to gain intensity upon reduction to the $\mathbf{1}^{-}$ state.

As alluded to above, the same type of behavior was observed for the $2^{n}$ series (Figure S7). Notably, the $\pi \rightarrow \pi^{*}(\mathrm{CN}-\mathrm{Me}-$ bpy) band in the UV region decreased in intensity upon the first reduction step and disappeared entirely upon the second one when both $\mathrm{CN}-\mathrm{Me}$-bpy ligands had undergone reduction. The NIR absorption due to $\mathrm{CN}-\mathrm{Me}-\mathrm{bpy}^{\bullet-}$ concomitantly increased without any significant change in the band shape [save for a red shift from $\sim 6300 \mathrm{~cm}^{-1}\left(2^{+}\right)$to $\sim 6060 \mathrm{~cm}^{-1}$ $\left(2^{0}\right)$ ] until the third reduction when bpy ${ }^{\bullet-}$-based absorption(s) set in and a broad shoulder emerged around 4300 $\mathrm{cm}^{-1}$, which extended into the IR. Interestingly, the UV absorption band attributable to the CN-Me-bpy ${ }^{\circ-} \pi \rightarrow \pi^{*} /$ MLCT transition fully developed only in $\mathbf{2}^{\mathbf{0}}$, corresponding to the redox level at which both $\mathrm{CN}-\mathrm{Me}$-bpy ligands have been converted to their corresponding radical anions. Finally, the weak, broad feature observed near $3300 \mathrm{~cm}^{-1}$ in $2^{+}$ disappeared upon reduction to $\mathbf{2}^{\mathbf{0}}$, consistent with its assignment as a CN-Me-bpy ${ }^{\bullet-} \rightarrow \mathrm{CN}-\mathrm{Me}-$ bpy ILCT transition.

Comparison of the Excited and Singly Reduced States. The common localization of the optically excited electron in the ${ }^{3}$ MLCT state and the electron added upon reduction at a CN-Me-bpy ligand (Figure S3) is expected to induce comparable spectroscopic responses to optical excitation and reduction. 

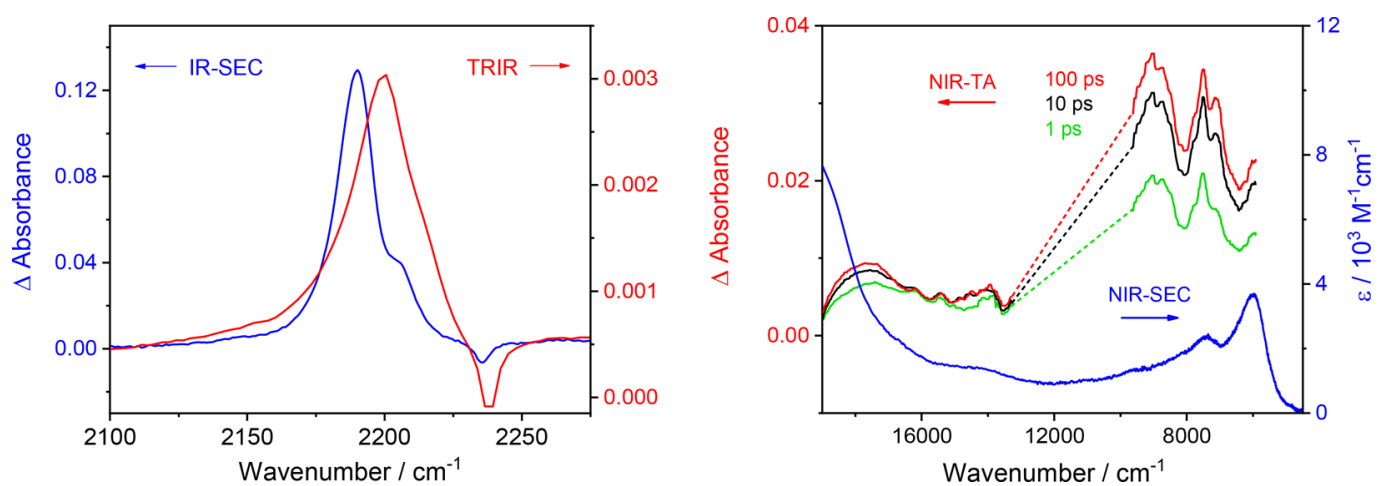

Figure 5. Comparison of the $\nu(\mathrm{C} \equiv \mathrm{N})$ IR and NIR spectra of $\mathbf{1}^{+}\left(\left[\mathrm{Ru}^{\mathrm{II}}\left(\mathrm{CN}-\mathrm{Mebpy}{ }^{\bullet-}\right)(\mathrm{bpy})_{2}\right]^{+}\right)$and $*^{*} \mathbf{1}^{2+}\left(*\left[\mathrm{Ru}^{\mathrm{III}}\left(\mathrm{CN}-\mathrm{Me}-\mathrm{bpy}{ }^{\bullet-}\right)(\mathrm{bpy})_{2}\right]^{2+}\right)$. Left: Difference IR spectra (after minus before excitation/reduction) of $\mathbf{1}^{+}$(blue) spectroelectrochemically generated in THF/TBAH and of $* 1^{2+}$ (red) measured by TRIR at 100 ps after $490 \mathrm{~nm}$ and $\sim 100 \mathrm{fs}$ excitation of $\mathbf{1}^{2+}$ in nitromethane. ${ }^{13}$ Note the offset of the TRIR spectrum (left panel, right axis) due to low-energy electronic absorption. Right: NIR spectrum of $\mathbf{1}^{+}$(blue) and excited-state NIR difference time-resolved absorption spectra measured at 1,10 , and $100 \mathrm{ps}$ after $400 \mathrm{~nm} / 100 \mathrm{fs}$ excitation. Dotted lines indicate the dead region covered by neither the charge-coupled nor InGaAs detector and/or blocked around $800 \mathrm{~nm}$ by a notch filter to eliminate the white-light-continuum pumping beam.

With regard to the electronic spectra, similarities between the photoexcited and electrochemically reduced forms of these compounds are clearly identifiable. Enhanced near-UV absorption between 24000 and $26000 \mathrm{~cm}^{-1}$ due to a $\pi \rightarrow$ $\pi^{*} /$ MLCT transition associated with the CN-Me-bpy ${ }^{\bullet-}$ moiety has been noted previously, ${ }^{12}$ so we have focused on NIR absorption of the singly reduced and ${ }^{3}$ MLCT excited states of $\mathbf{1}^{2+}$ (Figure 5, right). Compound $\mathbf{1}^{+}$exhibits a strong and broad NIR absorption with a shoulder at $9400 \mathrm{~cm}^{-1}$ and maxima at $7400 \mathrm{~cm}^{-1}\left(\varepsilon=2340 \mathrm{M}^{-1} \mathrm{~cm}^{-1}\right)$ and $6040 \mathrm{~cm}^{-1}$ $\left(3670 \mathrm{M}^{-1} \mathrm{~cm}^{-1}\right)$ that we assigned to $\mathrm{CN}-\mathrm{Me}-\mathrm{bpy}{ }^{\bullet-}$-localized $\pi \rightarrow \pi^{*}$ and CN-Me-bpy ${ }^{\bullet-} \rightarrow$ bpy ILCT transitions (Table S1). Excited-state NIR spectra showed features at similar energies (ca. 9000, 7500, 7140, and $\sim 6000 \mathrm{~cm}^{-1}$; the detection range ended at $5920 \mathrm{~cm}^{-1}$ ). In addition, a weak, monotonously decreasing background in the TRIR spectrum indicated the presence of absorption of an electronic origin extending into the IR region. TDDFT calculation on relaxed (UKSoptimized) $* 1^{2+}$ predicted the most intense triplet-triplet transition at $8853 \mathrm{~cm}^{-1}(f=0.11)$, which is predominantly $\pi$ $\rightarrow \pi^{*} \mathrm{CN}-\mathrm{Me}-\mathrm{bpy}^{\bullet-}$ in nature (Table S3). Highly mixed $\pi \rightarrow$ $\pi^{*}$ transitions involving contributions from CN-Me-bpy ${ }^{\bullet-} \rightarrow$ bpy ILCT and CN-Me-bpy ${ }^{\circ-} \rightarrow \mathrm{Ru}^{\mathrm{III}}$ LMCT excitations were calculated at $10556 \mathrm{~cm}^{-1}(0.003)$ and $11524 \mathrm{~cm}^{-1}(0.012)$. Much weaker transitions were calculated on the low-energy side of the NIR band: CN-Me-bpy ${ }^{\bullet-} \rightarrow$ bpy ILCT at 5920

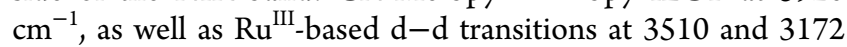
$\mathrm{cm}^{-1}$ (Table S3).

In the IR region, formation of the ${ }^{3} \mathrm{MLCT}$ state after optical excitation shifts the $\nu(\mathrm{C} \equiv \mathrm{N})$ band to lower energy, splits its $A_{1}$ and $B_{1}$ components (the symmetric and antisymmetric stretching vibrations of the two $\mathrm{CN}$ groups of a single $\mathrm{CN}-\mathrm{Me}$ bpy ligand, respectively), and increases their integrated intensity in a manner analogous to that observed spectroelectrochemically (Figure 5, left; Tables 2 and 3). The Lorentzian band shape was retained upon excitation as well as the first reduction of either complex, indicating that neither of these processes increases the solvational heterogeneity around $-\mathrm{C} \equiv$ $\mathrm{N}$ groups on the IR time scale. This behavior is common for all three investigated complexes, ${ }^{12,13}$ and the following discussion will concentrate on $\mathbf{1}^{2+}$.

The excitation-induced $\nu(\mathrm{C} \equiv \mathrm{N})$ shift of $\mathbf{1}^{2+}$ was smaller $\left(-38 \mathrm{~cm}^{-1}\right)$ than that upon reduction $\left(-46 \mathrm{~cm}^{-1}\right)$. The $A_{1}-B_{1}$ splitting appeared to be comparable, but only a rough estimate was possible for the excited state because of a larger linewidth. The integrated area of the $\nu(\mathrm{C} \equiv \mathrm{N})$ band showed a 7 -fold increase for $* 1^{2+}$ versus the $\sim 33$ times increase observed upon electrochemical reduction to $\mathbf{1}^{+}$. This behavior was closely matched by DFT vibrational analysis (Table 3), which correctly predicted the attenuated perturbation of $\nu(\mathrm{C} \equiv \mathrm{N})$ IR features upon excitation to the lowest-energy ${ }^{3} \mathrm{MLCT}$ excited state [shifts of $-31 \mathrm{~cm}^{-1}\left(\mathrm{~A}_{1}\right)$ and $-46 \mathrm{~cm}^{-1}\left(B_{1}\right), B_{1} /$ $A_{1}$ intensity ratio of 11 , and a 15 -fold total intensity enhancement in $* 1^{2+}$ relative to $1^{2+}$ compared to reduction $\left[-35 \mathrm{~cm}^{-1}\left(A_{1}\right)\right.$ and $-51 \mathrm{~cm}^{-1}\left(B_{1}\right), B_{1} / A_{1}$ intensity ratio of 6 , and a 32 -fold total intensity enhancement in $\mathbf{1}^{+}$.

The downshift of the $\nu(\mathrm{C} \equiv \mathrm{N})$ IR band upon reduction or MLCT excitation is a consequence of population of the $\pi^{*}(\mathrm{CN}-\mathrm{Me}-\mathrm{bpy}) \mathrm{LUMO}$, which is partly localized at the aromatic $\mathrm{C} 4$ and $\mathrm{C} 4^{\prime}$ atoms and at the terminal $\mathrm{N}$ atoms. It is weakly antibonding to the $\mathrm{C} \equiv \mathrm{N}$ bonds and $\pi$-bonding toward the $\mathrm{C}-\mathrm{CN}$ bonds (see $\alpha$-HOSO in Figures S8 and S9), so that its population weakens the $\mathrm{C} \equiv \mathrm{N}$ bonds, shifting $\nu(\mathrm{C} \equiv \mathrm{N})$ downward. The actual $\nu(\mathrm{C} \equiv \mathrm{N})$ shift magnitude depends on the extent of LUMO delocalization over the $-\mathrm{C} \equiv \mathrm{N}$ group(s). A smaller shift observed for $\mathbf{1}^{2+}-3^{2+}$ upon optical excitation than the first reduction is easily understood given the stronger electron-withdrawing effect of the $\mathrm{Ru}^{\mathrm{III}}$ center in $* \mathbf{1}^{2+}$ (formally described as $*\left[\mathrm{Ru}^{\mathrm{III}}\left(\mathrm{CN}-\mathrm{Me}-\mathrm{bpy}{ }^{\bullet-}\right)(\mathrm{bpy})_{2}\right]^{2+}$ ) compared to $\mathrm{Ru}^{\mathrm{II}}$ in $\mathbf{1}^{+}\left(\left[\mathrm{Ru}^{\mathrm{II}}\left(\mathrm{CN}-\mathrm{Me}-\mathrm{bpy}{ }^{\circ-}\right)(\mathrm{bpy})_{2}\right]^{+}\right)$coupled with the fact that the covalency of the metal-ligand bond results in less than a full unit of charge being transferred from the metal to the ligand upon MLCT excitation. This was supported by a less negative Mulliken charge at each $-\mathrm{C} \equiv \mathrm{N}$ in the ${ }^{3}$ MLCT excited state $* 1^{2+}(-0.054 \mathrm{e})$ than in the oneelectron-reduced form $\mathbf{1}^{+}(-0.075 \mathrm{e})$, as calculated by DFT. Lifting the degeneracy between the $A_{1}$ and $B_{1}$ modes upon reduction or excitation is also attributable to the delocalized unpaired electron density in the $\pi^{*}$ LUMO over both $\mathrm{C} \equiv \mathrm{N}$ groups, which mediates coupling between their stretching vibrations.

When the IR behaviors of $\mathbf{1}^{2+}-3^{2+}$ are compared, it is interesting to note that charge-transfer (CT) excitation of donor-acceptor compounds with a single $-\mathrm{C} \equiv \mathrm{N}$ group bound to a single aromatic ring results in much larger $\nu(\mathrm{C} \equiv$ $\mathrm{N}$ ) downshifts in the range $100-130 \mathrm{~cm}^{-1}$. This is the case of 
the twisted intramolecular charge-transfer (TICT) excited state in 4-(dimethylamino)benzonitrile and its derivatives in polar solvents, whose $\nu(\mathrm{C} \equiv \mathrm{N})$ IR band also shows a moderate intensity enhancement upon excitation. ${ }^{30,31}$ Excitation of $\left[\mathrm{W}(\mathrm{CO})_{5}(\mathrm{pyCN})\right]$ to a ${ }^{3} \mathrm{MLCT}$ state results in a shift of $-124 \mathrm{~cm}^{-1}$, as was determined by time-resolved resonance Raman spectroscopy. ${ }^{32}$

The IR intensity enhancement upon reduction or oxidation has been described for molecular species such as terphenyl, ${ }^{33}$ conjugated oligomers and polymers of fluorene and thiophene, ${ }^{34}$ and various conducting polymers as well as for vibrations of bridging groups in mixed-valence complexes, ${ }^{35,36}$ partially oxidized tetrakis(ferrocenylethynyl)ethene, ${ }^{37}$ and porphyrin oligomers, ${ }^{38}$ whose one-electron oxidation enhanced the IR band due to the stretching vibration of the $-\mathrm{C} \equiv \mathrm{C}-$ linker about 40 times. In the present case, the $\nu(\mathrm{C} \equiv \mathrm{N})$ IR band intensified about 35 times upon the first reduction and 5-7 times upon excitation to the ${ }^{3}$ MLCT lowest excited state, mostly because of intensity enhancement of the $B_{1}$ antisymmetric stretching vibration of the two terminal $-\mathrm{C} \equiv$ $\mathrm{N}$ groups. This effect is attributable to an increased dipolemoment derivative along the $B_{1}$ normal coordinate upon occupancy of the delocalized $\pi^{*}$ LUMO. The extra electron density is delocalized over the aromatic bpy core and the terminal $\mathrm{N}$ atoms of the $-\mathrm{C} \equiv \mathrm{N}$ groups (Figure $\mathrm{S} 3$ and $\alpha$ HOSO in Figures S8 and S9). A higher electron density at the terminal $\mathrm{N}$ atoms will magnify the changes of the local dipoles upon $\mathrm{C} \equiv \mathrm{N}$ bond elongation (contraction). More importantly, the $\mathrm{C} \equiv \mathrm{N}$ stretching motion will cause $\pi^{*}$ electron density shifting over the whole $\mathrm{CN}-\mathrm{Me}-\mathrm{bpy}{ }^{\bullet-}$ ligand, resulting in large dipole-moment changes. This effect will be stronger for the antisymmetric $B_{1}$ mode because the electron-density redistribution (push) upon contraction of one $-\mathrm{C} \equiv \mathrm{N}$ group will be magnified by a pull toward the elongating second one, resulting in larger $B_{1}$ than $A_{1}$ enhancement. This effect is absent for the parent complex where the $\pi^{*}$ LUMO is unoccupied, the two $-\mathrm{C} \equiv \mathrm{N}$ groups are uncoupled, and the IR intensity originates from the global dipole-moment change of the whole complex, as indicated by the higher $A_{1}$ than $B_{1}$ intensity. DFT implemented in Gaussian16 calculates IR intensities using derivatives of the electron density with respect to nuclear displacements. ${ }^{39,40}$ Experimental enhancement factors obtained for the reduction and excitation of $\mathbf{1}^{2+}$ were comparable or slightly smaller than DFT-calculated values (Table 3 ), suggesting that the above explanation of the reduction/excitation-induced IR-intensity enhancement based on increasing dipole-moment derivatives is sufficient, without the need to invoke mechanisms arising from interactions with low-lying electronic transitions. ${ }^{41,42}$

\section{CONCLUDING REMARKS}

The $\left[\mathrm{Ru}(\mathrm{CN}-\mathrm{Me}-\mathrm{bpy})_{x}(\mathrm{bpy})_{3-x}\right]^{2+}$ series of complexes comprise an electrochemically rich family of compounds exhibiting one oxidation step ${ }^{12}$ and up to five reduction steps. The 400$500 \mathrm{meV}$ gap between CN-Me-bpy and bpy $\pi^{*}$ LUMO, together with evidence for weak ligand-ligand interactions, at best support the notion that reduction steps are localized at single $\mathrm{CN}-\mathrm{Me}$-bpy ligand(s); in heteroleptic complexes, the bpy ligand becomes reduced only after all of the CN-Me-bpy units in a given compound (one in the case of compound $\mathbf{1}^{2+}$ or both for compound $\mathbf{2}^{2+}$ ) have been converted to their corresponding radical anions. Species with one-electronreduced $\mathrm{CN}-\mathrm{Me}$-bpy ligands (including $3^{-}=\left[\mathrm{Ru}^{\mathrm{II}}(\mathrm{CN}-\mathrm{Me}-\right.$ bpy $\left.\left.^{\bullet-}\right)_{3}\right]^{-}$) appear to be chemically stable. This behavior is promising for further spectroscopic studies (e.g., electron paramagnetic resonance or two-dimensional IR), as well as for potential use in electrocatalysis or in applications that could exploit their electrochromism.

Localization of the reduction steps inferred from redoxpotential values and their spacing was confirmed spectroelectrochemically, with the $\nu(\mathrm{C} \equiv \mathrm{N})$ IR band, UV features due to $\pi \rightarrow \pi^{*}$ (CN-Me-bpy)- and $\pi \rightarrow \pi^{*}$ (bpy)-based transitions, and NIR transitions associated with CN-Me-bpy ${ }^{\bullet-}$ and bpy ${ }^{\bullet-}$ being most diagnostic. Of special interest are the $\mathrm{CN}-\mathrm{Me}$ bpy $^{\bullet-} \rightarrow$ CN-Me-bpy ILCT electronic transition found in the IR spectra of $3^{+}, 3^{0}$, and $2^{+}$, which demonstrates the simultaneous presence of reduced and unreduced $\mathrm{CN}-\mathrm{Me}-$ bpy ligands, and the $\nu(\mathrm{C} \equiv \mathrm{N})$ vibrational mode, which provides information specific to the CN-Me-bpy ligand and its radical anion.

Long-lived, strongly emissive lowest triplet excited states ${ }^{12}$ $* 1^{2+}, 2^{2+}$, and $* 3^{2+}$ have MLCT character, with the excited electron localized at a single $\mathrm{CN}-\mathrm{Me}$-bpy ligand similarly to the corresponding one-electron-reduced products $1^{+}, 2^{+}, 3^{+}$ (Figure S3). Common electron localization rationalizes the observed similar spectroscopic responses to excitation and the first reduction, which are especially prominent in the IR region where both reduction and optical excitation result in a red shift and intensity enhancement of the $\nu(\mathrm{C} \equiv \mathrm{N})$ band.

Finally, it should be noted that the $-\mathrm{C} \equiv \mathrm{N}$ group is a convenient IR probe of solvation and environment effects using one- or two-dimensional IR spectroscopy, as well as vibrational Stark spectroscopy, ${ }^{6,7,43-46}$ but its utility as an IRactive molecular tag is somewhat diminished by a low IR intensity and a Fermi resonance. ${ }^{47}$ Complexes $1^{2+}-3^{2+}$ demonstrate that $-\mathrm{C} \equiv \mathrm{N}$ substituents on a bpy ligand also are effective reporters of intramolecular changes of the electron-density distribution. The large $\nu(\mathrm{C} \equiv \mathrm{N})$ intensity enhancement observed upon reduction facilitates the detection of $\nu(\mathrm{C} \equiv \mathrm{N})$ IR features and opens an opportunity for IR investigations of solvation dynamics or supramolecular interactions of radical-anionic species and CT excited states, as well as for kinetic studies of photoinduced electron-transfer processes using IR spectroscopy.

\section{ASSOCIATED CONTENT}

\section{Supporting Information}

The Supporting Information is available free of charge at https://pubs.acs.org/doi/10.1021/acs.inorgchem.0c03579.

$\mathrm{CVs}$ of $\mathbf{2}^{2+}$ and $3^{2+}$, calculated spin-density distributions in $\mathbf{1}^{+}$and $* 1^{2+}$, additional NIR SEC results, UV-visNIR spectroelectrochemistry of $\mathbf{2}^{2+}$, TDDFT-calculated NIR electronic transitions of $\mathbf{1}^{+}$and $* 1^{2+}$, and shapes of spectroscopically relevant spin orbitals (PDF)

\section{AUTHOR INFORMATION}

\section{Corresponding Authors}

František Hartl - Department of Chemistry, University of Reading, Reading RG6 6DX, United Kingdom; 이이.org/ 0000-0002-7013-5360; Email: f.hartl@reading.ac.uk

Antonín Vlček - School of Biological and Chemical Sciences, Queen Mary University of London, E1 4NS London, United Kingdom; J. Heyrovský Institute of Physical Chemistry, Academy of Sciences of the Czech Republic, CZ-18223 
Prague, Czech Republic; ๑ orcid.org/0000-0002-64138311; Email: a.vlcek@qmul.ac.uk

\section{Authors}

James O. Taylor - Department of Chemistry, University of Reading, Reading RG6 6DX, United Kingdom

Martin Pižl - J. Heyrovský Institute of Physical Chemistry, Academy of Sciences of the Czech Republic, CZ-18223 Prague, Czech Republic; Department of Inorganic Chemistry, University of Chemistry and Technology, Prague, CZ-16628 Prague, Czech Republic

Miroslav Kloz - ELI Beamlines, Institute of Physics, Czech Academy of Sciences, CZ-18200 Prague, Czech Republic; ๑ orcid.org/0000-0003-4609-8018

Mateusz Rebarz - ELI Beamlines, Institute of Physics, Czech Academy of Sciences, CZ-18200 Prague, Czech Republic; (- orcid.org/0000-0002-5823-2432

Catherine E. McCusker - Department of Chemistry, Michigan State University, East Lansing, Michigan 48824, United States; ๑ orcid.org/0000-0002-0471-9034

James K. McCusker - Department of Chemistry, Michigan State University, East Lansing, Michigan 48824, United States; @ orcid.org/0000-0002-5684-3117

Stanislav Záliš - J. Heyrovský Institute of Physical Chemistry, Academy of Sciences of the Czech Republic, CZ-18223 Prague, Czech Republic; $\odot$ orcid.org/0000-0003-43453205

Complete contact information is available at: https://pubs.acs.org/10.1021/acs.inorgchem.0c03579

\section{Notes}

The authors declare no competing financial interest.

\section{ACKNOWLEDGMENTS}

This work was supported by EPSRC (UK) Grants EP/ R029687/1 and DPT/GS16-014 (jointly with Spectroelectrochemistry Reading, a spin-out company of the University of Reading), Czech Ministry of Education (MSMT) Grant LTAUSA18026, and Projects ELIBIO (CZ.02.1.01/0.0/0.0/ 15_003/0000447) and ADONIS (CZ.02.1.01/0.0/0.0/ 16_019/0000789) from the European Regional Development Fund and MŠMT, within targeted support of large infrastructures. Quantum-chemical calculations were supported by MŠMT through Project "e-Infrastructure CZ-LM2018140" at the IT4Innovations National Supercomputing Center. J.K.M. gratefully acknowledges support from the Chemical Sciences, Geosciences, and Biosciences Division, Office of Basic Energy Sciences, Office of Science, U.S. Department of Energy, through Grant DE-FG02-01ER15282.

\section{DEDICATION}

This paper is dedicated to Prof. Wolfgang Kaim (Universität Stuttgart, Germany) at the occasion of his 70th birthday.

\section{REFERENCES}

(1) Chen, P.; Omberg, K. M.; Kavaliunas, D. A.; Treadway, J. A.; Palmer, R. A.; Meyer, T. J. Insights on the Excited State Electronic Structures of Ruthenium(II) Polypyridine Complexes Obtained by Step-Scan Fourier Transform Infrared Absorption Difference TimeResolved Spectroscopy. Inorg. Chem. 1997, 36, 954-955.

(2) Omberg, K. M.; Schoonover, J. R.; Treadway, J. A.; Leasure, R. M.; Dyer, R. B.; Meyer, T. J. Mid-Infrared Spectrum of $\left[\mathrm{Ru}(\mathrm{bpy})_{3}\right]^{2+}$. J. Am. Chem. Soc. 1997, 119, 7013-7018.
(3) Omberg, K. M.; Schoonover, J. R.; Bernhard, S.; Moss, J. A.; Treadway, J. A.; Kober, E. M.; Dyer, R. B.; Meyer, T. J. Mid-Infrared Spectrum of $\left[\mathrm{Ru}(\mathrm{phen})_{3}\right]^{2+*}$. Inorg. Chem. 1998, 37, 3505-3508.

(4) Kiefer, L. M.; Kubarych, K. J. Two-dimensional infrared spectroscopy of coordination complexes: From solvent dynamics to photocatalysis. Coord. Chem. Rev. 2018, 372, 153-178.

(5) Pagano, P.; Guo, Q.; Kohen, A.; Cheatum, C. M. Oscillatory Enzyme Dynamics Revealed by Two-Dimensional Infrared Spectroscopy. J. Phys. Chem. Lett. 2016, 7, 2507-2511.

(6) Fried, S. D.; Boxer, S. G. Measuring Electric Fields and Noncovalent Interactions Using the Vibrational Stark Effect. Acc. Chem. Res. 2015, 48, 998-1006.

(7) Ghosh, A.; Ostrander, J. S.; Zanni, M. T. Watching Proteins Wiggle: Mapping Structures with Two-Dimensional Infrared Spectroscopy. Chem. Rev. 2017, 117, 10726-10759.

(8) Kiefer, L. M.; Kubarych, K. J. Solvent Exchange in Preformed Photocatalyst-Donor Precursor Complexes Determines Efficiency. Chem. Sci. 2018, 9, 1527-1533.

(9) Kämper, S.; Paretzki, A.; Fiedler, J.; Záliš, S.; Kaim, W. Solar Cell Sensitizer Models $\left[\mathrm{Ru}(\text { bpy-R })_{2}(\mathrm{NCS})_{2}\right]$ Probed by Spectroelectrochemistry. Inorg. Chem. 2012, 51, 2097-2104.

(10) Kaim, W.; Klein, A. Spectroelectrochemistry; Royal Society of Chemistry, 2008.

(11) Kaim, W.; Fiedler, J. Spectroelectrochemistry: the best of two worlds. Chem. Soc. Rev. 2009, 38, 3373-3382.

(12) McCusker, C. E.; McCusker, J. K. Synthesis and Spectroscopic Characterization of CN-Substituted Bipyridyl Complexes of $\mathrm{Ru}(\mathrm{II})$. Inorg. Chem. 2011, 50, 1656-1669.

(13) Brown, A. M.; McCusker, C. E.; Carey, M. C.; BlancoRodríguez, A. M.; Towrie, M.; Clark, I. P.; Vlček, A.; McCusker, J. K. Vibrational Relaxation and Redistribution Dynamics in Ruthenium(II) Polypyridyl-Based Charge-Transfer Excited States: A Combined Ultrafast Electronic and Infrared Absorption Study. J. Phys. Chem. A 2018, 122, 7941-7953.

(14) Krejčík, M.; Daněk, M.; Hartl, F. Simple construction of an infrared optically transparent thin-layer electrochemical cell: Applications to the redox reactions of ferrocene, $\mathrm{Mn}_{2}(\mathrm{CO})_{10}$ and $\mathrm{Mn}$ $(\mathrm{CO})_{3}(3,5 \text {-di-t-butyl-catecholate })^{-}$. J. Electroanal. Chem. Interfacial Electrochem. 1991, 317, 179-187.

(15) Frisch, M. J.; Trucks, G. W.; Schlegel, H. B.; Scuseria, G. E.; Robb, M. A.; Cheeseman, J. R.; Scalmani, G.; Barone, V.; Petersson, G. A.; Nakatsuji, H.; Li, X.; Caricato, M.; Marenich, A. V.; Bloino, J.; Janesko, B. G.; Gomperts, R.; Mennucci, B.; Hratchian, H. P.; Ortiz, J. V.; Izmaylov, A. F.; Sonnenberg, J. L.; Williams-Young, D.; Ding, F.; Lipparini, F.; Egidi, F.; Goings, J.; Peng, B.; Petrone, A.; Henderson, T.; Ranasinghe, D.; Zakrzewski, V. G.; Gao, J.; Rega, N.; Zheng, G.; Liang, W.; Hada, M.; Ehara, M.; Toyota, K.; Fukuda, R.; Hasegawa, J.; Ishida, M.; Nakajima, T.; Honda, Y.; Kitao, O.; Nakai, H.; Vreven, T.; Throssell, K.; Montgomery, J. A., Jr.; Peralta, J. E.; Ogliaro, F.; Bearpark, M. J.; Heyd, J. J.; Brothers, E. N.; Kudin, K. N.; Staroverov, V. N.; Keith, T. A.; Kobayashi, R.; Normand, J.; Raghavachari, K.; Rendell, A. P.; Burant, J. C.; Iyengar, S. S.; Tomasi, J.; Cossi, M.; Millam, J. M.; Klene, M.; Adamo, C.; Cammi, R.; Ochterski, J. W.; Martin, R. L.; Morokuma, K.; Farkas, O.; Foresman, J. B.; Fox, D. J. Gaussian16, revision A.03; Gaussian, Inc.: Wallingford, CT, 2016.

(16) Becke, A. D. Density-Functional Thermochemistry. III. The Role of Exact Exchange. J. Chem. Phys. 1993, 98, 5648-5652.

(17) Lee, C.; Yang, W.; Parr, R. G. Development of the ColicSalvetti Correlation-Energy Formula into a Functional of the Electron Density. Phys. Rev. B: Condens. Matter Mater. Phys. 1988, 37, 785789.

(18) Andrae, D.; Häussermann, U.; Dolg, M.; Stoll, H.; Preuss, H. Energy-Adjusted ab initio Pseudopotentials for the Second and Third Row Transition Elements. Theor. Chim. Acta 1990, 77, 123-141.

(19) Krishnan, R.; Binkley, J. S.; Seeger, R.; Pople, J. A. SelfConsistent Molecular Orbital Methods. XX. A Basis Set for Correlated Wave Functions. J. Chem. Phys. 1980, 72, 650-654. 
(20) Cossi, M.; Rega, N.; Scalmani, G.; Barone, V. Energies, Structures, and Electronic Properties of Molecules in Solution with the C-PCM Solvation Model. J. Comput. Chem. 2003, 24, 669-681.

(21) Vlček, A., Jr.; Zálišs, S. Modeling of Charge Transfer Transitions and Excited States in d6 Transition Metal Complexes by DFT Techniques. Coord. Chem. Rev. 2007, 251, 258-287.

(22) Vlček, A. A. Ligand Based Redox Series. Coord. Chem. Rev. 1982, 43, 39-62.

(23) Gaš, B.; Klíma, J.; Zálišs, S.; Vlček, A. A. Redox Series of Complexes with a Mixed Coordination Sphere. J. Electroanal. Chem. Interfacial Electrochem. 1987, 222, 161-171.

(24) Zálišs, S.; Krejčík, M.; Drchal, V.; Vlček, A. A. The Sequence of Ligand Reductions in Heteroleptic Ruthenium-Diimine Complexes: Calculation of Redox Potentials as a Diagnostic Tool. Inorg. Chem. 1995, 34, 6008-6014.

(25) Krejčík, M.; Vlček, A. A. Electrochemistry of $\left[\left(\mathrm{Ru}(\mathrm{bpy})_{2}\right)\right.$ $\mathrm{bpm}]\left(\mathrm{PF}_{6}\right)_{4}$. Complete Assignment of Individual Reduction Steps. Inorg. Chem. 1992, 31, 2390-2395.

(26) Vlček, A., Jr. Electron-transfer processes in mononuclear polypyridine-type metal complexes. In Electron Transfer in Chemistry.; Balzani, V., Astruc, D., Eds.; Wiley-VCH: Weinheim, Germany, 2001; Vol. 2, pp 804-877.

(27) Záliš, S.; Drchal, V. A Model Calculation of Redox Potential Sequence of Systems with Mutually Interacting Redox Centers: $\mathrm{M}(\text { bpy })_{3}{ }^{(2-n)+}$ Systems. Chem. Phys. 1987, 118, 313-323.

(28) Zálišs, S.; Consani, C.; El Nahhas, A.; Cannizzo, A.; Chergui, M.; Hartl, F.; Vlček, A., Jr. Origin of Electronic Absorption Spectra of MLCT-Excited and One-Electron Reduced 2,2'-bipyridine and 1,10phenanthroline Complexes. Inorg. Chim. Acta 2011, 374, 578-585.

(29) Heath, G. A.; Yellowlees, L. J.; Braterman, P. S. Spectroelectrochemical Studies on Tris-bipyridyl Ruthenium Complexes; Ultra-violet, Visible, and Near-infrared Spectra of the Series $\left[\mathrm{Ru}(\text { bipyridyl })_{3}\right]^{2+/ 1+/ 0 / 1-}$. J. Chem. Soc., Chem. Commun. 1981, 287289.

(30) Hashimoto, M.; Hamaguchi, H. Structure of the TwistedIntramolecular-Charge-Transfer Excited Singlet and Triplet States of 4-(Dimethylamino)benzonitrile As Studied by Nanosecond TimeResolved Infrared Spectroscopy. J. Phys. Chem. 1995, 99, 7875-7877. (31) Kwok, W. M.; Ma, C.; George, M. W.; Grills, D. C.; Matousek, P.; Parker, A. W.; Phillips, D.; Toner, W. T.; Towrie, M. Further timeresolved spectroscopic investigations on the intramolecular charge transfer state of 4-dimethylamino-benzonitrile (DMABN) and its derivatives, 4-diethylaminobenzonitrile (DEABN) and 4-dimethylamino-3,5-dimethylbenzonitrile (TMABN). Phys. Chem. Chem. Phys. 2003, 5, 1043-1050.

(32) Zálišs, S.; Busby, M.; Kotrba, T.; Matousek, P.; Towrie, M.; Vlček, A., Jr. Excited State Characters and Dynamics of $\left[\mathrm{W}(\mathrm{CO})_{5}(4-\right.$ cyano-pyridine $)]$ and $\left[\mathrm{W}(\mathrm{CO})_{5}\right.$ (piperidine) $]$ Studied by Picosecond Time-Resolved IR and Resonance Raman Spectroscopy and TD-DFT Calculations. Roles of W->L, W->CO MLCT and LF Excited States Revised. Inorg. Chem. 2004, 43, 1723-1734.

(33) Sakamoto, A.; Harada, T.; Tonegawa, N. A New Approach to the Spectral Study of Unstable Radicals and Ions in Solution by the Use of an Inert Gas Glovebox System: Observation and Analysis of the Infrared Spectra of the Radical Anion and Dianion of pTerphenyl. J. Phys. Chem. A 2008, 112, 1180-1187.

(34) Zamadar, M.; Asaoka, S.; Grills, D. C.; Miller, J. R. Giant infrared absorption bands of electrons and holes in conjugated molecules. Nat. Commun. 2013, 4, 2818.

(35) Londergan, C. H.; Salsman, J. C.; Ronco, S.; Kubiak, C. P. Infrared Activity of Symmetric Bridging Ligand Modes in PyrazineBridged Hexaruthenium Mixed-Valence Clusters. Inorg. Chem. 2003, 42, 926-928.

(36) Rocha, R. C.; Shreve, A. P. Characterization of infrared vibrational activity in specific totally symmetric bridging modes of mixed-valence systems near the localized-to-delocalized transition. Chem. Phys. 2006, 326, 24-32.

(37) Vincent, K. B.; Gluyas, J. B. G.; Gückel, S.; Zeng, Q.; Hartl, F.; Kaupp, M.; Low, P. J. Tetrakis(ferrocenylethynyl)ethene: Synthesis,
(Spectro)electrochemical and quantum chemical characterisation. J. Organomet. Chem. 2016, 821, 40-47.

(38) Peeks, M. D.; Tait, C. E.; Neuhaus, P.; Fischer, G. M.; Hoffmann, M.; Haver, R.; Cnossen, A.; Harmer, J. R.; Timmel, C. R.; Anderson, H. L. Electronic Delocalization in the Radical Cations of Porphyrin Oligomer Molecular Wires. J. Am. Chem. Soc. 2017, 139, 10461-10471.

(39) Amos, R. D. SCF Dipole Moment Derivatives, Harmonic Frequencies and Infrared Intensities for $\mathrm{C}_{2} \mathrm{H}_{2}$ and $\mathrm{C}_{2} \mathrm{H}_{4}$. Chem. Phys. Lett. 1985, 114, 10-14.

(40) Amos, R. D.; Handy, N. C.; Jalkanen, K. J.; Stephens, P. J. Efficient Calculation of Vibrational Magnetic Dipole Transition Moments and Rotational Strengths. Chem. Phys. Lett. 1987, 133, 21-26.

(41) Peticolas, W. L.; Nafie, L. A.; Stein, P.; Fanconi, B. Quantum Theory of the Intensities of Molecular Vibrational Spectra. J. Chem. Phys. 1970, 52, 1576-1584.

(42) Nafie, L. A. Theory of Vibrational Circular Dichroism and Infrared Absorption: Extension to Molecules with Low-Lying Excited Electronic States. J. Phys. Chem. A 2004, 108, 7222-7231.

(43) Kim, H.; Cho, M. Infrared Probes for Studying the Structure and Dynamics of Biomolecules. Chem. Rev. 2013, 113, 5817-5847.

(44) Waegele, M. M.; Tucker, M. J.; Gai, F. 5-Cyanotryptophan as an infrared probe of local hydration status of proteins. Chem. Phys. Lett. 2009, 478, 249-253.

(45) Deb, P.; Haldar, T.; Kashid, S. M.; Banerjee, S.; Chakrabarty, S.; Bagchi, S. Correlating Nitrile IR Frequencies to Local Electrostatics Quantifies Noncovalent Interactions of Peptides and Proteins. J. Phys. Chem. B 2016, 120, 4034-4046.

(46) Bagchi, S.; Boxer, S. G.; Fayer, M. D. Ribonuclease S Dynamics Measured Using a Nitrile Label with 2D IR Vibrational Echo Spectroscopy. J. Phys. Chem. B 2012, 116, 4034-4042.

(47) Andrews, S. S.; Boxer, S. G. Vibrational Stark Effects of Nitriles I. Methods and Experimental Results. J. Phys. Chem. A 2000, 104, 11853-11863. 